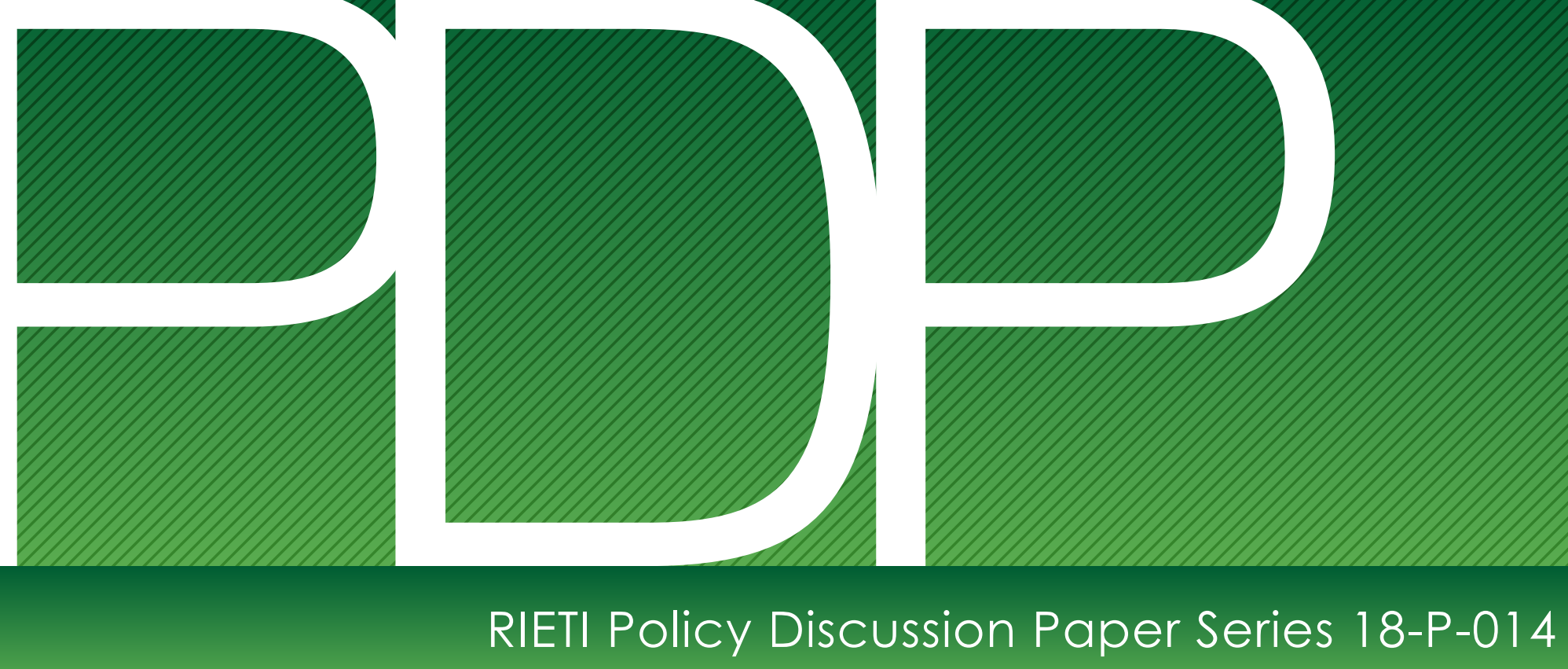

Determinants of survival ratio for de jure standards: AI-related technologies and interaction with patents (Revised)

TAMURA Suguru

RIETI

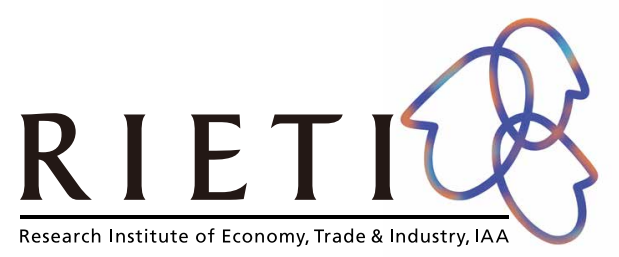

The Research Institute of Economy, Trade and Industry https://www.rieti.go.jp/en/ 


\title{
Determinants of survival ratio for de jure standards: AI-related technologies and interaction with patents
}

\author{
Suguru TAMURA \\ RIETI (Research Institute of Economy, Trade and Industry)
}

\begin{abstract}
In this study, I focus on the characteristics of standardized technologies and the effective terms of regional de jure standards to discuss the effectiveness of their management system. To this end, I analyze the determining factors considering the Japanese Industrial Standards of approximately 14,000 cases. I conduct a semi-parametric survival analysis to study the determinants of the effective term. The results demonstrate that the technological category and type of technical standards (e.g., production and designs and symbols) significantly affect the effective term. International standards, legislative use, and a standard essential patent (SEP) are also shown to have significant influence on it. Moreover, the technological category of AI-related standards is established. I also discuss the difference between AI-related standards and non-AI-related standards. The effective term of AI-related technologies is found to be significantly shorter. These findings contribute to the design of better global and regional standards management processes.
\end{abstract}

Keywords: de jure standards, survival analysis, AI-related standards, SEP

JEL: O25, O30, O38.

RIETI Policy Discussion Papers Series is created as part of RIETI research and aims to contribute to policy discussions in a timely fashion. The views expressed in these papers are solely those of the author(s), and neither represent those of the organization to which the author(s) belong(s) nor the Research Institute of Economy, Trade and Industry.

This study was conducted as part of the Research Institute of Economy, Trade and Industry (RIETI), Japan. The author appreciates the support of Directors Morita, Saito and Saito of the Technical Regulations, Standards and Conformity Assessment Unit at the Ministry of Economy, Trade and Industry (METI), Japan. This work was supported by JSPS KAKENHI Grant Number 15K03718 and 19K01827.

E-mail: tamura.edu@nifty.com 


\section{INTRODUCTION}

This study discusses better management of de jure standards. It explores not only the differences between artificial intelligence (AI)- related standards and non-AI-related standards but also the differences between standard essential patent (SEP)- related standards and non-SEP-related standards. I use the Japanese regional de jure standards system (i.e., Japanese Industrial Standards [JIS]) to analyze this issue because the bibliographic data of the system are well-organized in the form of electrical data. ${ }^{1,2}$ The other reason is that Japan is one of the major contributors to setting global de jure standards.

I propose an improvement in the management of de jure standards to promote the supply of de jure standards as public goods in stock bases. Generally, standards are classified into two categories based on their formation process (i.e., de facto and de jure). De facto standards are formed due to market competition [2]. De facto standards define the specifications of a technology in the market. ${ }^{3}$

De jure standards are formed by the standards-writing organization and de facto standards are formed within the market regardless of the existence of a specific organization with proprietary interest [3]. The significance of de jure standards to GDP growth has also been discussed in the literature [4]. Its stock number is positively correlated to GDP growth in the EU [4].

I focus on system's improvement in order to increase de jure standards stock numbers. In this study, the regional de jure standards management system (i.e., JIS) is discussed as a prelude to improvements in the international de jure standards management system because the harmonization of the management system of international organizations (e.g., the International Organization for Standardization [ISO] and the International Electrotechnical Commission [IEC]) with regional de jure standards (e.g., JIS) is an issue that deserves more attention. A proper synchronization will improve knowledge flows across countries and promote more frequent foreign direct investments.

$\mathrm{JIS}^{4}$ are classified as de jure standards (de jure standards are mainly developed by public agencies or the national government.) Standard development organizations (SDO) for de jure standards often works on a for-profit basis (e.g., ISO and JIS). Therefore, the management efficiency of SDO needs to be considered when we discuss the formation and management of the standards. In particular, this study focuses on reducing the management cost of SDO's activities after standards formation (e.g., the related cost of SDO's secretariat's activities) [5]. I mainly focus on the expansion of review intervals for de jure standards, because this will reduce the incurred cost both in SDOs and related firms. ${ }^{5,6}$ The expansion of review or inspection intervals is a conventional method to reduce the management cost.

While discussing the standards management system, I assume that the post-formation management cost for existing de jure standards is one of the factors that can hinder the creation of new ones. ${ }^{7}$ I do not discuss their yearly production rate but their number as stock figure, as discussed in previous studies [4]. We infer that the resources used for their formation doubled in the 1980s in the US [8]. This point is relevant to JIS as well as international de jure SDOs.

\footnotetext{
${ }^{1}$ In this article, I will use the expression "standards" for the adjectival usage of the noun "standard” because the expression of standards + noun is used widely and is an accepted conventional expression (e.g., American National Standards Institute [ANSI]).

2 The number of de jure standards in Japan is currently stable at about 10,000 [1]. This demonstrates a certain level of knowledge accumulation and supply of standards as public goods.

${ }^{3}$ Hence, a de facto standard is not necessarily specified uniquely.

${ }^{4}$ JIS are based on the Industrial Standardization Law, which defines the rules for the formation and management of the standards.

${ }^{5}$ For example, firms can reduce the cost related to travel to participate in an SDO meeting.

${ }^{6}$ Previous literature has focused more on the formation of standards [6][7], while post-formation management efficiency has not been discussed in detail.

${ }^{7}$ This is because the de jure SDO uses revenue from sales of standards booklet to produce new standards. This implies that the resources to establish new de jure standards are not available unconditionally.
} 
The expansion of review intervals is a necessary condition, but it is not a necessary and sufficient condition for the formation of new standards, because there are other related influential factors (e.g., business strategy and social interactions) that affect formation [5]. Nevertheless, this policy option is useful to resolve the bottleneck to the improvement of the stock number of de jure standards.

I discuss this issue in terms of the JIS system because this discussion is critical in JIS management, owing to the limitation of administrative resources in the system. The JIS system selected for analysis provides a robust bibliographic dataset. By law, JIS are reviewed every five years to decide whether they should be extended or withdrawn. This process involves a muchawaited decision on the necessity of the standard by a specially convened government council (the Japan Industrial Standards Committee [JISC]).

Since this is a highly labor- and time-intensive process, ${ }^{8,9}$ the number of new standards could be increased by reducing the management's workload from the existing standards. Reforming the JIS review system is a possible solution to increase the total stock number of JIS. For example, ANSI comprises a thousand corporate members. The SDO needs to collect, distribute, and adjust the standards set by such member organizations and industries [8]. By reduction of such management works, the residual human resources could be transferred from the management of existing standards to the formulation of new standards.

One policy option is to extend the five-year review period for technological categories. Reduction of the management cost according to technological categories would help reduce this administrative work. ${ }^{10}$ This method of cost reduction is conventionally used in machinery inspections [10].

This study therefore questions whether or not the appropriate review interval for technological categories of standards differs. The technological standards are classified into specific categories. However, review intervals are fixed, regardless of these categories. Intuitively, the obsolescence of technology differs categorically [3]. I will address this issue statistically through the econometric analysis of de jure standards' survival rate.

In addition, I consider emerging technologies to determine the extent of their influence on effective terms. I reclassify the technological category and create a new group linked with AI to understand the effects of this significant technology. Owing to the rapid development of AI technologies, it is expected that the effective term of the technological category of AI will become shorter.

Further, I will analyze the influence of the types of standards. The dynamic role of standards has been previously discussed in terms of innovation adoption [11] and classified into (1) anticipatory standards (to solve the expected interoperability problems), (2) enabling standards (to extend robustness and scale of goods), and (3) responsive standards (to improve efficiencies or reduce market uncertainties). In this study, I pay attention to the type of standards, following the framework of the dynamic role of standards, to identify the influence of type on the effective terms.

Standards are categorized using the bibliographic data into measurement, production, and design and symbol types. For example, measurement and production types of standards include specifications for the evaluation of numeric efficiency and production methodology. In contrast, standards for designs and symbols include the graphical expression. Standardized designs and symbols are socially and publicly used.

Designs and symbols are significantly related to the intangible assets of firms, such as the brand.

\footnotetext{
${ }^{8}$ The resulting review period sometimes differs from five years because the review process involves administrative tasks. Hence, the time required for the review process is not always as originally planned.

${ }^{9}$ Human resources, which can be employed for the management task of reviews, are actually exiguous. Specifically, the number of workers in the Japanese government is limited by a law on national government organization. Since JIS are primarily managed by a Japanese government department, it is quite difficult to address any labor shortage by just increasing the number of workers.

${ }^{10}$ Note that JIS now include 19 technological categories, and its classification is different from that of ISO [1][9].
} 
In this context, we can consider these standards as a type of brands at the social level. Brands of consumer goods are developed and controlled by private firms and help increase the profits of each firm, while standardized designs and symbols, as public brands, promote social welfare. This implies that appropriate standards management for designs and symbols plays an important role in social welfare. Therefore, this factor is worth discussing in relation to effective standards management.

I also discuss the references to other legal factors (e.g., international standards, legislative usage, and an SEP), because the effective term of a standard can be related to the associated legal frameworks. Of these, I pay special attention to the interplay between standards and patents, considering an SEP as one of the determinants. As an SEP is a part of this framework through connected patents, it can have a longer effective term.

For the analysis of data, I use survival analysis, specifically the Cox hazard proportional model [12]. This model is common in the analysis of survival data because it does not require specifying the functional form for estimation (i.e., the Cox hazard proportional model is semiparametric) [13]. I use primary numerical data related to JIS to conduct an empirical analysis.

We can expand the review interval of technological categories and reduce their frequency and the related administrative costs if the difference is found significant. This will contribute to effective standards management after formation. Moreover, if the effective terms are shorter than the current terms, we can shorten them in the technological category.

The expected result is that the technological category comprising electrical and information engineering including AI technologies, shows shorter effective terms [2] and the ICT lifecycle is shortening [3] because of the changeability of such standards owing to uncertainties in technological development and application [5]. On the other hand, the effective terms of the materials industry are expected to be longer. If this expectation is correct, the review intervals of this industry may be extended beyond those of the current terms, which will, in turn, reduce the workload in the technological category.

The remainder of this paper is structured as follows. Section 2 provides an overview of existing literature and builds the hypotheses. Section 3 describes the model employed along with the data. Section 4 illustrates and discusses the results of the empirical estimation. Section 5 explains the limitations of the study and avenues for future research. Section 6 presents the conclusions and policy implications of the study.

\subsection{Factors affecting the effective terms}

\section{LITERATURE REVIEW AND HYPOTHESES}

Several qualitative studies on de facto standards have discussed the effective terms of technical standards in line with technological change across generations [2][14][15]. For example, research on the arrangement of letters on a keyboard has shown that the existing key arrangement system has lasted for about 100 years. ${ }^{11}$ Suarez and Utterback [14] investigate the standardization of the typewriter and its relationship with the lifetime of enterprises. Yamada and Kurokawa [2] consider the formation and effective terms of Japanese de facto standards in electrical and electronic equipment. Specifically, they focus on the standardization of various data storage media (e.g., CD, DVD, and VCR) and their players. Among these standards, floppy disks have the longest effective term (24 years). On the other hand, Betamax VCR has the shortest effective term (three years). The analysis shows that the longer the effective term, the greater the benefits gained from the standard. However, although the authors evaluate the effective term with criteria based on establishment and abolishment, verifiable quantitative evidence related to specific calendar dates is not provided. The data which I use in this study include specific calendar dates of the formation and withdrawal of standards.

Moreover, for information-processing products (i.e., VCR, video disc, and game hardware), de

\footnotetext{
${ }^{11}$ It was pointed out that the key arrangement (i.e., QWERTY) is ergonomically inefficient. Its sustainability is explained by the lock-in effects of human skills [15].
} 
facto standards are established after capturing 2\%-3\% of the market. This seems to support the argument that a de facto standard would be established easily if companies raise their market shares quickly [2]. Nevertheless, those studies deal with relatively conventional information-processing products in de facto standards rather than de jure standards. More important technology areas (e.g., AI-related technologies) have not been adequately explored. In this study, JIS technological groups are hypothetically reconstructed, and a new category (i.e., AI-related engineering) is added to the existing technological classifications. ${ }^{12}$

\subsection{Other factors}

This study assumes that, as with the technological category, the length of the effective term might be potentially affected by the functional difference of standards. Previously, the role of standards has been discussed in terms of innovation adoption [11]. Three roles of standards are discussed: (1) anticipatory standards (to solve the expected interoperability problems), (2) enabling standards (to extend the robustness and scale of goods), and (3) responsive standards (to improve efficiency or reduce market uncertainties).

In this study, I examine the type of standards (e.g., (1) measurement, (2) production, and (3) design and symbol). Standards related to measurement are generally regarded as more persistent than other types. This is due to the fact that data generated by de jure measurement standards are often used for legislative purposes. Since law requires continuity, changes to standards that might affect legislation should be minimized. This discussion presents the idea that such standards have longer effective terms.

Nevertheless, there is another aspect to the discussion: when new technologies are introduced (e.g., nanotechnology), it is necessary to develop standards related to the measurements of new technologies, especially in the case of disruptive innovation [16]. This discussion presents the idea that measurement standards can have shorter effective terms.

In addition to such standards, this study covers standards that define the basic images of goods and services (i.e., design and symbol standards). The design and symbol standards are worth considering in view of the essential role of designs and symbols in the services industry, which currently accounts for a major proportion of economic growth.

Moreover, references to legal factors (i.e., international standards, legislative use, and relation to $S E P$ ) are discussed as determinants. Since international standards improve trade [17], they have recently become more essential in trade facilitation as a result of international harmonization of public procurement. Nevertheless, the influence of international standards on JIS is not discussed in the previous literature in terms of survival analysis. Thus, I survey it in this study. As for their influence on standards effective terms, I assume that the international reference has the longer influence because the regional de jure standards are connected to international standards through the harmonization of the World Trade Organization. This implies that changes in these standards require time. As a result, effective terms result in longer terms.

Another legal issue is citation in law. For example, standards related to quality are often referred to in related laws and regulations to assure product safety [18]. JIS are referred to approximately 6,500 times in legislative usage [1]. ${ }^{13}$ Thus, JIS require stability, and legislative citation is considered to have a longer influence on the effective term of JIS.

Further, there is another legal interaction. This interaction is attributed to SEP. An SEP does not necessarily represent the whole interaction between standards and patents [19]. ${ }^{14}$ There is a wider interaction between the two, but in this study, I use an SEP in order to discuss the influence of patents, because the data related to an SEP are available in a robust form. Under SEP, standards are

\footnotetext{
${ }^{12}$ Technological classifications of JIS [1].

${ }^{13}$ The Pharmaceutical Affairs Law, for example, contains several references.

${ }^{14}$ In sum, there is interaction between standards and patents outside an SEP.
} 
connected to patents in a formal declaration in an SDO, and thus, legal reference occurs. ${ }^{15}$ Since legislative reference has longer influence on effective terms, the SEP is also thought to have longer influence on the effective terms.

\subsection{Hypotheses}

Considering abovementioned literature, I discuss the hypotheses in terms of factors that influence survival rates of standards.

Hypothesis 1: The survival rate of standards has been differently influenced by the technological groups to which they belong.

Hypothesis 2: The survival rate of standards has been differently influenced by the type of standards.

Hypothesis 3: The survival rate of standards has been differently influenced by the legal factors of standards.

\subsection{Methods}

\section{METHODS AND DATA}

With regard to the review period, I perform econometric estimation with primary data related to the effective term of de jure standards. I assume the existence of a functional relationship between (1) the effective term of technical standards and (2) their technological category and other related factors as discussed in the previous research for the EU [20]. Through a Cox proportional hazard model, the influence of the technological classification is examined [12]. The model is widely used in epidemiological research. However, it has also been employed in applied economics research (e.g., the study of the relationship between M\&A and innovation [21] and the study of the relationship between the dominant design and firms' survival [14]).

The Cox hazard proportional model has advantages for the estimation. First, the model does not require the specification of the hazard function. Second, when the information of the survival time is available, it is preferred over the logistic model because it can use all the available information including survival time, although the logistic model results in summarizing data into a binominal outcome $(0,1)$. This means that the Cox hazard proportional model can use more information from the data than the logistic model. These points are relevant to this study because the hazard functional form is not specified and data related to the survival time are available [13].

\subsection{Model}

The hazard ratio is defined as the ratio of the number of observation objects that generate an event between time $t$ and time $t+1$ to the existing number of observation objects at time $t$. In other words, if the event of interest is the death of a patient, a high hazard ratio indicates that from time $t$ to time $t$ +1 , the rate of deaths among patients is high. On the other hand, when the hazard ratio is low, the proportion of deceased patients is low. The model can be described as follows:

$$
h(t)=h_{0}(t) \exp (\boldsymbol{X} \boldsymbol{\beta}) \text {, }
$$

where $\boldsymbol{X}$ is a variable matrix, $\boldsymbol{\beta}$ is a parameter matrix, and $h_{0}(t)$ is some time-dependent functional form for the baseline hazard ratio in the Cox proportional hazard model.

The hazard model checks whether a category of technical standards significantly affects the hazard ratio. ${ }^{16}$ The dependent variable (i.e., time to failure) is the effective term of the technical standard (i.e., the time interval between the establishment and the withdrawal). Blind's research on standards used survival analysis related to standards in the EU [20]. The author analyzes the factors that contribute to the effective term of technical standards related to both information communication and communication equipment [20]. In Blind's research, the related data are retrieved from

\footnotetext{
${ }^{15}$ SEPs are a special case of patents related to standards. Strictly speaking, this discussion is on de jure standards, which include SEPs.

${ }^{16}$ A proportional hazard relationship is assumed in this analysis.
} 
PERINORM, a database for the management of de jure standards [22]. ${ }^{17,18}$

In the specifications of the model to be estimated, I include (1) technological classification, (2) standards function, and (3) reference to legal usage (i.e., international standards [international], legislative usage [legislative], and an SEP [sep] ), as shown in Table 1. I select these policy variables, which can influence effective terms, from the general observations and from previous research results [20].

\section{[Insert Table 1]}

As for expected influences, the difference in technological classification can have a longer or shorter influence because the technological characteristic has a different effect on the effectiveness of standards. Standards types are also important because the measurement method often defines the value of the scientific quantities. This implies that the measurement standards do not change frequently and the effective terms of such standards are longer than those of other types of standards (e.g., production and designs and symbols). Moreover, in estimation models, the influence of the year when the standard was formed (i.e., the influence of the economic background on each cohort) was controlled with a dummy variable.

I prepared eight models (i.e., four models depending on the conventional technological category and the other four on the categories including AI-related technologies) to estimate the influence of the above-described policy factors. Table 2 shows the summary of variables in each model. ${ }^{19}$

\section{[Insert Table 2]}

The main difference between models is in whether the variables - the type of standards, and the legal reference-are included or not. Further, the models with and without SEP are presented as Model 1.3., 1.4., 2.3., and 2.4. to test the influence of the SEP on the effective term. The statistical software STATA is used for the estimation.

\subsection{Data}

I employ JIS data as of 2014, which comprise about 14,000 JIS formulated in the past, including previously withdrawn and currently active ones. ${ }^{20}$ The effective term of standards is defined as the difference between their formation and withdrawal time. The existing duration is used as the effective term for unwithdrawn standards. The effective term is a continuing variable.

The dataset includes standards established before 2009 (i.e., whose effective term is longer than five years). As a result, it is possible to avoid truncation owing to the five-year review interval. ${ }^{21}$ Since the latest standards usually have not been exposed to reviews, they may, if included, produce a downward bias in terms of the effective term. As for the SEP, data as of 2006 are used owing to limitations of data availability. ${ }^{22,23}$

I use the JIS technological grouping for the technological classification and add AI-related engineering to the technological groups. A few examples of contents of technologies in each

\footnotetext{
${ }^{17}$ PERINORM is the de jure standards database maintained for management purpose by the EU nations.

${ }^{18}$ Several existing studies use the bibliographic data of JTC 1 and PERINORM.

${ }^{19}$ I have not included the interaction terms among international, legislative and SEP in the models because the purpose of the models is not to see the interaction effects among these variables.

${ }^{20}$ The data are retrieved from e-JISC, which is maintained and prepared for the management of JIS by the JISC.

${ }^{21}$ A small number of standards are reviewed before the initial five years after formation owing to administrative reasons.

${ }^{22}$ The standards considered include patents registered as an SEP.

${ }^{23}$ The dataset included the standards established before 2009 to avoid the right-hand truncation bias. In this study, there is a year difference between standards information and SEP information owing to the data availability of SEPs. Although the bias may not seem zero between the established year and the SEP information date, related bias is negligible because the gap of eight years is not so large compared to standards effective terms.
} 
technological area of JIS are summarized in Table A.1. (Appendix A) [23]. For the preparation of the AI-related engineering group, I check the title of standards and select the technologies related to AI. The identified technologies are mainly applied technologies of AI (e.g., image processing and database technologies).

The International Patent Classification (IPC) has been used in previous patent analysis to group AI-related technologies and to identify AI-related patents [24] [25]. ${ }^{24}$ In extant research, the IPC class related to AI includes G06N 3/00 (Biological model), G06N 5/00 (Knowledge-based model), G06N 7/00 (Specific mathematical model), and G06N 99/00 (Other AI technologies) [24]. Nevertheless, JIS are not labeled with IPC. Hence, I use the title name to determine the group of each technology. Then, I move the identified AI-related standards from the original group to the AI-related engineering group. As a result, the number of AI-related standards is 105 as of 2014 in Table B.1. and Figure. C.1. (Appendix B and C). ${ }^{25,26}$

Concerning standards functions, the standards are classified by type through keyword matching, based on the words in the title of each standard. Specifically, when words related to designs and symbols are detected, the standards are categorized as design and symbol standards. Moreover, words related to measurement are associated with measurement standards. The other categories are residually classified as production standards. Concerning the coding of the international reference, as well as the legislative usage and SEP, I use the e-JISC database information and a related document [26].

The descriptive statistics of the dependent and independent variables in each model are summarized in Table 3. The mean effective term of JIS is about 30 years, a number that is much larger than the current review period of five years. It is worth noting that this evidence may positively support the usefulness of extending the review period suggested in this study.

\section{[Insert Table 3]}

\section{RESULTS AND DISCUSSION}

I show the results in Table 4.1. (i.e., case 1) and Table 4.2. (i.e., case 2: AI-related engineering group is included). ${ }^{27}$ The tables indicate $0.1 \%, 1 \%, 5 \%$, and $10 \%$ significance levels. The contents of each technology are summarized in Table A.1. (Appendix A). In the description, it is important to note that the categorization is according to the technological characteristics and not along the conventional industrial categorization. Therefore, the results indicate the nature of the technological characteristics rather than that of the industrial characteristics of examined standards.

When the hazard ratio is greater than 1, it implies that the effective term of the category tends to be shorter. When, instead, the hazard ratio is less than 1 , the opposite occurs. Automotive engineering and ferrous materials and metallurgy show the hazard ratio of $0.4-0.5$. This means that the hazard event is 0.5 times likely to occur than the base case.

The number of failures indicates the number of standards that have experienced the hazard event "withdrawal," while the other standards are right-censored, meaning that they are valid until the observation period ends. In the sample, about 4,500 standards have experienced withdrawal.

[Insert Table 4.1 and Table 4.2]

The overall summary of the estimations is shown in Table 5.

\footnotetext{
${ }^{24}$ IPC is a classification guideline prepared by the World Intellectual Property Organization (WIPO).

25 Those standards have effective terms that are longer than five years.

${ }^{26}$ Six standards are reclassified from the current B: Mechanical Engineering and 99 standards from the current X: Information Processing.

27 "Civil Engineering and Architecture" is used as the baseline because the technology group has the largest number of standards in the group.
} 


\section{[Insert Table 5]}

\subsection{Technological classification}

Hypothesis 1 is supported. According to the estimation results, some technical standards groups, such as "Ferrous Materials and Metallurgy," have longer effective terms than the baseline category in both the cases 1 and 2. Although the result is relative to the baseline category, it still suggests that the review period of this group can be extended to more than the current five years. Even, in the prior study, the average time to form the national and international de jure standards is about 2.5 to 5 years and 7 years, respectively [27]. Considering this, the current five-year interval seems relatively short. Moreover, the de jure standards achieve more coordination when formed because the formation time is long [3]. This means that the standards have already matured and stabilized when they are formed.

On the other hand, the effective period of technical standards tends to be shorter in categories such as "Information Processing" when compared to the baseline category. In the reclassification, many standards of the "AI-related Engineering” group (i.e., AI-related standards) are recategorized from "Information Processing." The AI-related Engineering also shows a significantly shorter effective term in case 2. This result reflects the fact that a technological update in the standardized AI-related technology is nearly as fast as that of the information processing technology.

\subsubsection{Analysis of estimation}

The results of the analysis for the difference of hazard ratio for each group are shown in Table 6 . The table only shows the technological category with a significant $p$-value. The difference from the baseline is analyzed as follows:

Difference from baseline $=$ the hazard ratio of a technology group - the baseline hazard ratio

$$
=\text { the hazard ratio of a technology group }-1 \text {, }
$$

where the baseline hazard ratio is 1 . The difference from the baseline can be positive or negative. When the ratio is positive, the hazard ratio is larger than 1 , and the withdrawal of the standards happens more than that in the base case. Conversely, when the figure is negative, the withdrawal of the standards happens less than that in the baseline technological group.

\section{[Insert Table 6]}

In the table, automotive engineering shows the largest negative value of the difference from the baseline, followed by ferrous materials and metallurgy and ceramics. These technological fields are potential areas to expand the review interval. The technological categories of information processing and AI-related engineering show one of the largest positive values; this result implies that technological obsolescence happens frequently in these groups. Shorter review intervals and more frequent technological updates will therefore increase the benefit of standards to users. Overall, the difference between the smallest and largest hazard ratios derived from technological groups appears large, implying that technological difference is an important factor in the system design of the de jure standards management.

In the discussion of the results, it is noted that the AI-related technology may comprise relatively new technologies, and thus the effective term of the technology is considered shorter than those of conventional technologies. In sum, in the interpretation of the result, the bias of the emergent period of new technology is carefully considered. However, the technology's decades-long history mitigates the bias to an extent because AI technology has a long history, with the first boom in the 1960s. The current AI-technology boom is, in fact, the third, although the central technology has been different for each boom.

Moreover, concerning the reason behind automotive engineering having a long effective term, the standard in the category is still mechanics and does not include the standards related to autonomous 
driving. Hence, the tendency is different from that of information processing and AI-related engineering. If automotive technology and information processing were merged frequently in standards, the effective term of automotive engineering could shorten in the long-run. This observed result shows the difficulty of the technology fusion beyond technological categories [16]. Although the standards for fusion technologies were not generally formulated with ease, in the past Japanese firms developed new products by combing technologies beyond existing technology areas [28]. Nevertheless, at least in de jure standardized technologies in automotive and AI-related technologies, the fusion still does not seem to have been sufficiently improved.

Finally, this result implies that the new grouping in this analysis is meaningful and that there is an academic and practical need for new classification codes for AI-related technologies. Currently, the ISO classification does not include AI technology codes, which is different from the IPC. Therefore, the results also suggest a need to review the ISO classification [9]. ${ }^{28}$

\subsection{Type of standards}

Hypothesis 2 is supported. The type of standard is shown to have a significant influence. Compared to the baseline (measurement standards), the design and symbol standards show a shorter tendency. The standards for production also exhibit a significant shorter tendency than measurement standards. Concerning the magnitude of difference, the difference in the hazard ratio between design and production is smaller than $10 \%$. The difference is significant but is relatively smaller than that of technological groups.

\subsection{Legal reference}

Concerning the influence of legal reference, all three have a significantly longer tendency. SEP has a longer tendency than international. Hypothesis 3 is supported. The result that standards including SEPs have longer effective terms is consistent with the previous research on ICT standards including SEPs [29]. In this study, the observed effect is confirmed with controlling for technology difference. In terms of the IP policy, it is implied that SEP holders are not likely to changes the standard because they can expect to earn royalties on the current standards under certain conditions.

\section{LIMITATION AND FURTHER STUDY}

This study is not free from limitations and there are the further research issues in the relation to those limitations. Although the contribution of the standards to macroeconomic growth is presented [4], the microeconomic cost-benefit analysis is another method that can be employed in future studies to find the precise management cost. Moreover, this study tacitly assumes the benefit of the standards constants. For a more precise discussion in future studies, it would be better to include an estimation model that includes the benefit from each standard.

The management issue related to the administrative cost reduction of SDOs, other than JIS, is an important research subject that examines the usefulness and generality of this policy option. De jure SDOs also exist, in which this management issue does not contribute toward the formation of new standards. However, the effort toward continuous administrative cost reduction is an important management issue in organizational management.

In the analysis of the new technology (e.g., AI-related technologies), the downward bias for shorter effective terms is not avoidable. For more detailed academic conclusions about effective terms, continued observation spanning over decades will be essential. This is the same for other emerging technologies.

Moreover, although it is desirable to use data with no time difference for the analysis, this research uses the SEP data as of 2006 due to data availability and constraints. A limitation of this study is that there may be bias owing to the time difference between 2014 and 2006.

${ }^{28}$ In the ISO classification, there are classifications-codes 31 (Electronics), 33 (Telecommunications), and 25 (Information technology)_but no specific categories and codes for AI. 
Future studies should also investigate the interaction between patents and standards more widely. In this study, I focus on an SEP and its influence on standards from a legal perspective. To determine the influence of patents on standards from a management perspective, taking a wider scope on the patents' interaction with standards may be necessary (i.e., non-legal interaction and legal interaction).

Finally, future research should also note that the number of patents in SEP standards may have an influence on the effective terms of standards. In this study, I use the data that only define standards including SEPs or otherwise, and I do not focus on the number of patents in a standard. If the number of patents in each SEP standard were available, we could examine the robustness of the influence of SEPs on standards effective terms more accurately.

\section{CONCLUSION AND POLICY IMPLICATIONS}

This article discusses the improvement of the de jure standards management system. Reducing administrative costs that are required for the management of existing de jure standards is one of the options to promote the formation of new technical standards.

The study has practical implications because the results indicate that specific technological groups tend to have longer effective terms. Therefore, differentiating the review period by technological groups is worth considering as an effective policy option to save related costs.

The theoretical contributions of this study are relevant to the technological adoption. The result shows the standards for fusion technologies are not well formed. This study points out that the lack of fusion technology standards for automotive and AI-related technologies may delays the market creation in the emerging area.

Finally, this study recognizes a promising new technology group (e.g., AI-related technology). A reclassification of the technological grouping is important, corresponding to the chronological change of essential technology in order to maintain an effective standards management system.

\section{Appendices:}

Appendix A:

[Insert Table A.1.]

Appendix B:

[Insert Table B.1.]

Appendix C:

[Insert Figure. C.1.]

Endnote: The list of AI-related standards (Table B.1.) can be downloaded from the homepage of RIETI (https://www.rieti.go.jp/en/publications/summary/18080001.html) for academic and educational purposes.

\section{Reference:}

[1] Japanese Industrial Standards Committee (2013). Japan's standardization policy 2013. Tokyo, Japan: Japanese Industrial Standards Committee.

[2] Yamada, H. and Kurokawa, S. (2005). How to profit from the de facto standard-based competition: Learning from Japanese firms' experiences. International Journal of Technology Management, 30(3-4), 299-326.

[3] Belleflamme, P. (2002). Coordination on formal vs. de facto standards: a dynamic approach. European Journal of Political Economy, 18(1),153-176.

[4] DIN. (2011). The Economic Benefits of Standardisation: An update of the study carried out by DIN in 2000. Berlin: DIN German Institute of Standardisation.

[5] Sherif, M. H., Jakobs, K., and Egyedi, T.M. (2007). Standards of quality and quality of standards 
for telecommunications and information technologies, In M. Hörlesberger, M. El-Nawawi, and T. Khalil (Eds.), Challenges in the Management of New Technologies (pp. 427-447), Singapore: World Scientific Publishing.

[6] Backhouse, J., Hsu C.W., and Silva, L. (2006). Circuits of power in creating de jure standards: Shaping an international information system of security standard. MIS Quarterly, 30, 413-438.

[7] Shin, D.H., Kimb, H., and Hwang, J. (2015). Standardization revisited: A critical literature review on standards and innovation. Computer Standards \& Interfaces, 38, 152-157.

[8] Farrell, J. and Saloner, G. (1988). Coordination through committees. The RAND Journal of Economics, 19 (2), 235-252.

[9] ISO. (2015). International classification for standards 2015. Geneva:ISO.

[10] Besnard, F. and Bertling, L. (2010). An approach for condition-based maintenance optimization applied to wind turbine blades. IEEE Transactions on Sustainable Energy, 1(2),7783.

[11] Egyedi, T. M. and Sherif, M. H. (2010). Standards' dynamics through an innovation lens: Next generation ethernet networks. IEEE Communications Magazine, 48(10),166-171.

[12] Cox, D.R. (1972). Regression models and life tables. Journal of Royal Statistical Society, B34, 187-220.

[13] Kleinbaum, D.G. and Klein, M. (2012). Survival Analysis: A Self-Learning Text, Third Edition. NY: Springer.

[14] Suarez, F.F. and Utterback, J. M. (1995). Dominant designs and the survival of firms. Strategic Management Journal, 16, 415-430.

[15] David, P.A. (1985). Clio and the economics of QWERTY, American Economics Review, 75, 332-337.

[16] Blind, K. and Gauch, S. (2009). Research and standardisation in nanotechnology: Evidence from Germany, The Journal of Technology Transfer, 34(3), 320-342.

[17] Blind, K. and Jungmittag, A. (2005). Trade and the impact of innovations and standards: The case of Germany and the UK. Applied Economics, 37(12),1385-1398.

[18] Maxwell, J.E. (1998). Minimum quality standards as a barrier to innovation. Economics Letters, $58,355-360$.

[19] Tamura, S. (2016). A new intellectual property metric for standardization activities. Technovation, 48-49, 87-98.

[20] Blind, K. (2008). Factors influencing the lifetime of telecommunications and information technology standards, In T.M. Egyedi and K. Blind (Eds.), The Dynamics of Standards (pp. 155177). Cheltenham: Edward Elgar Publishing.

[21] Puranam, P., Singh, H., and Zollo, M. (2006). Organizing for innovation: Managing the coordination-autonomy dilemma in technology acquisitions. Academy Management Journal, 49(2), 263-280.

[22] Egyedi, T.M. and Heijen, P. (2008). How stable are IT standard, In T.M. Egyedi and K. Blind (Eds.), The Dynamics of Standards (pp. 137-154). Cheltenham: Edward Elgar Publishing.

[23] Japanese Industrial Standards Committee. (2018). Kogyo hyojunka to JIS (Industrial standardization and JIS). Tokyo, Japan: Japanese Industrial Standards Committee. Obtained through the Internet: http://www.jisc.go.jp/jis-act/index.html [accessed 2018] (in Japanese).

[24] Fujii, H. and Managi, S. (2018). Trends and priority shifts in artificial intelligence technology invention: A global patent analysis. Economic Analysis and Policy, 58,60-69.

[25] Tseng, C. and Ting, P. (2013). Patent analysis for technology development of artificial intelligence: A country-level comparative study, Innovation: Management, Policy \& Practice, 15(4), 463-475.

[26] Ministry of Economy, Trade and Industry. (2009). Sentangijutsubunya ni okeru gijutsukaihatsu to hyojunka no kankei • mondai nikansuru chosa hokokusho (Research Report about Relation and 
Issues between Technology Development and Standards in the Field of Advanced Technologies). Tokyo: Ministry of Economy, Trade and Industry (in Japanese).

[27] David, P.A. and Shurner, M. (1996). Formal standard-setting for global telecommunications and information services. Telecommunications Policy, 20(10), 789-815.

[28] Kodama, F. (1992). Technology fusion and the new R\&D. Harvard Business Review, 70(4),70-78.

[29] Baron, J., Pohlmann, T., and Blind, K. (2016). Essential patents and standard dynamics. Research Policy, 45(9),1762-1773. 
Tables and Figures:

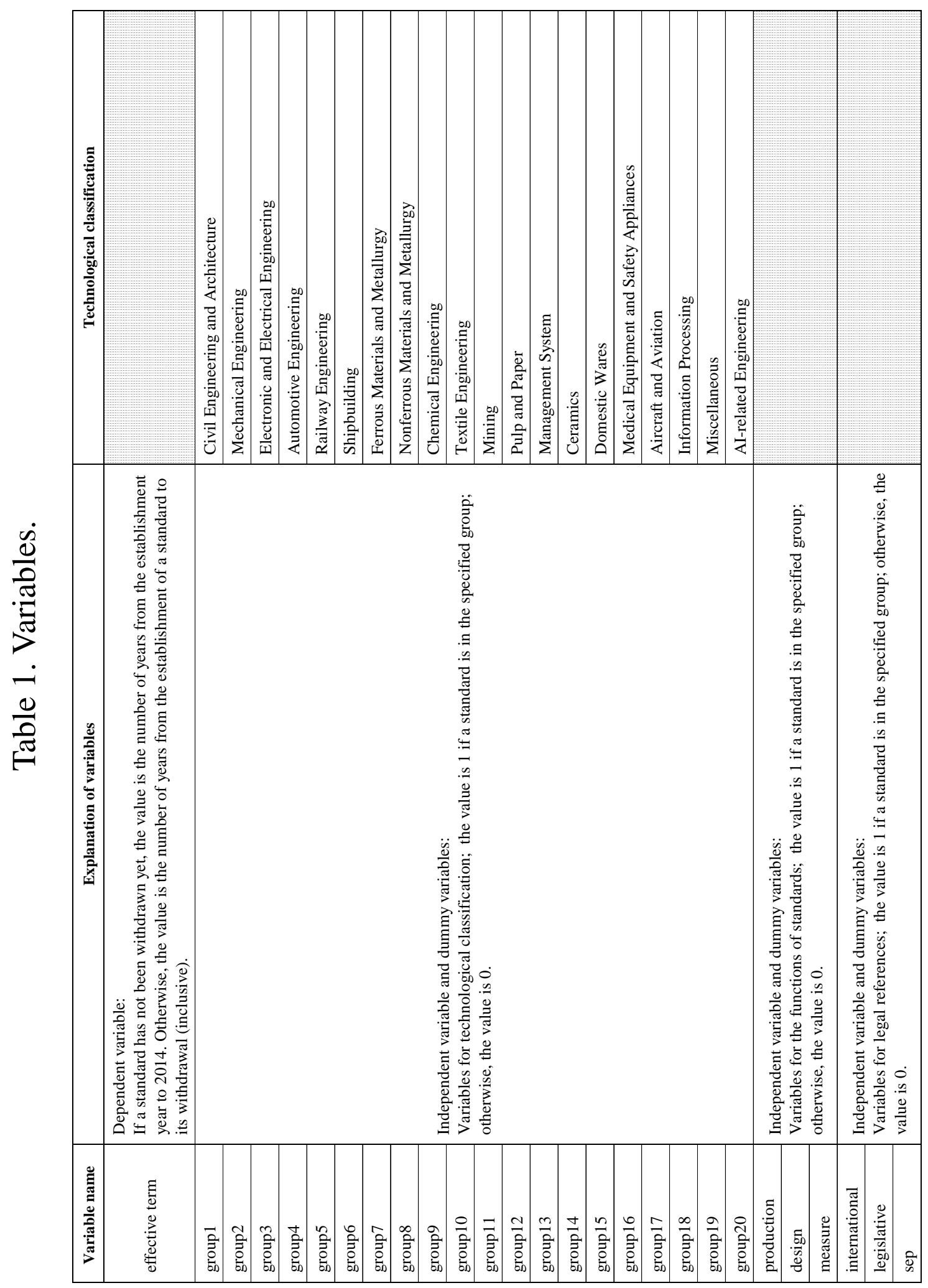


Table 2. Estimation models.

\begin{tabular}{|c|c|c|c|c|c|c|}
\hline & \multirow[b]{2}{*}{$\begin{array}{c}\text { Dependent } \\
\text { variable: } \\
\text { effective term }\end{array}$} & \multicolumn{4}{|c|}{ Independent variables } & \multirow{2}{*}{$\begin{array}{c}\begin{array}{c}\text { Control } \\
\text { variable }\end{array} \\
\\
\begin{array}{c}\text { Time dummy } \\
\text { of standards } \\
\text { formation } \\
\text { year }\end{array}\end{array}$} \\
\hline & & $\begin{array}{c}\text { Technological } \\
\text { classification } \\
\text { (dummy } \\
\text { variable) }\end{array}$ & $\begin{array}{c}\text { Type of } \\
\text { standards } \\
\text { (dummy } \\
\text { variable) }\end{array}$ & $\begin{array}{c}\text { Legal } \\
\text { reference } \\
\text { not including } \\
\text { SEP } \\
\text { (dummy } \\
\text { variable) }\end{array}$ & $\begin{array}{c}\text { Legal } \\
\text { reference } \\
\text { including } \\
S E P \\
\text { (dummy } \\
\text { variable) }\end{array}$ & \\
\hline \multirow{4}{*}{$\begin{array}{l}\text { Conventional } \\
\text { technological } \\
\text { grouping } \\
\text { (Case 1) }\end{array}$} & Model 1.1. & $\mathrm{X}$ & & & & $\mathrm{X}$ \\
\hline & Model 1.2. & $\mathrm{X}$ & & $\mathrm{X}$ & & $\mathrm{X}$ \\
\hline & Model 1.3. & $\mathrm{X}$ & $\mathrm{X}$ & $\mathrm{X}$ & & $\mathrm{X}$ \\
\hline & Model 1.4. & $\mathrm{X}$ & $\mathrm{X}$ & & $\mathrm{X}$ & $\mathrm{X}$ \\
\hline \multirow{4}{*}{$\begin{array}{l}\text { Technological } \\
\text { grouping } \\
\text { including AI- } \\
\text { related } \\
\text { technology } \\
\text { (Case 2) }\end{array}$} & Model 2.1. & $\mathrm{X}$ & & & & $\mathrm{X}$ \\
\hline & Model 2.2. & $\mathrm{X}$ & & $\mathrm{X}$ & & $\mathrm{X}$ \\
\hline & Model 2.3. & $\mathrm{X}$ & $\mathrm{X}$ & $\mathrm{X}$ & & $\mathrm{X}$ \\
\hline & Model 2.4. & $\mathrm{X}$ & $\mathrm{X}$ & & $\mathrm{X}$ & $\mathrm{X}$ \\
\hline
\end{tabular}

Note: " $\mathrm{X}$ " indicates that the variable is included in the model. 


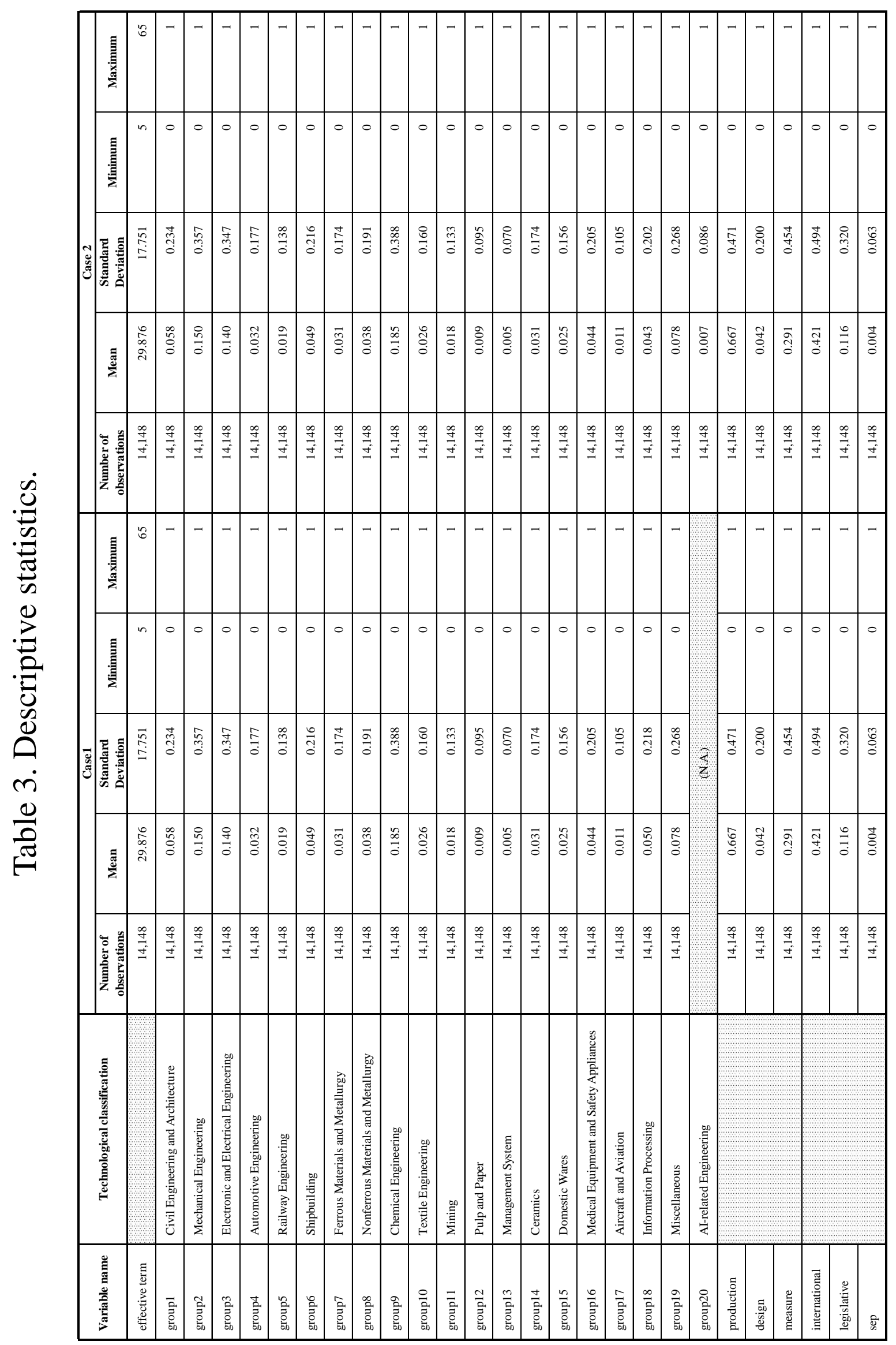




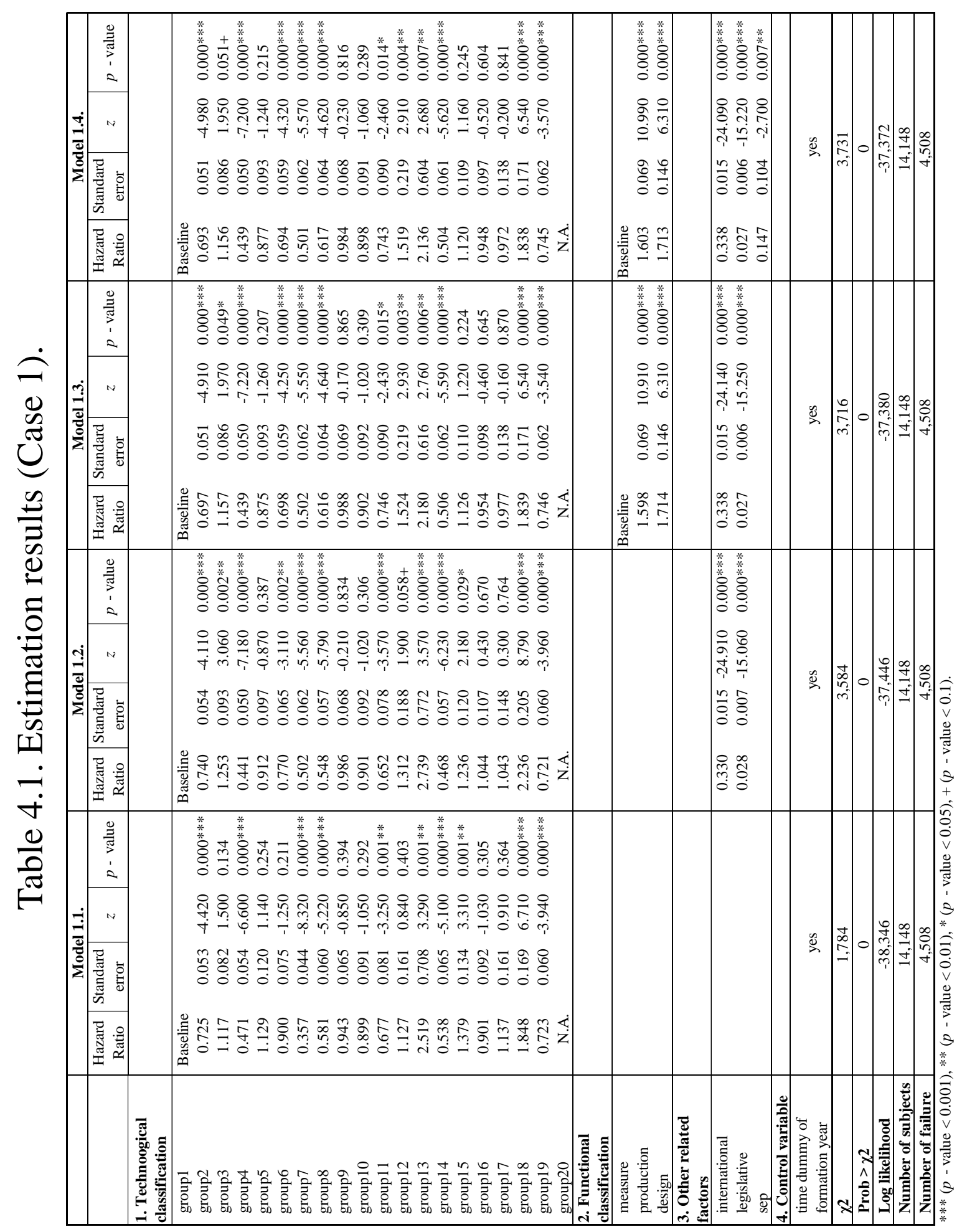




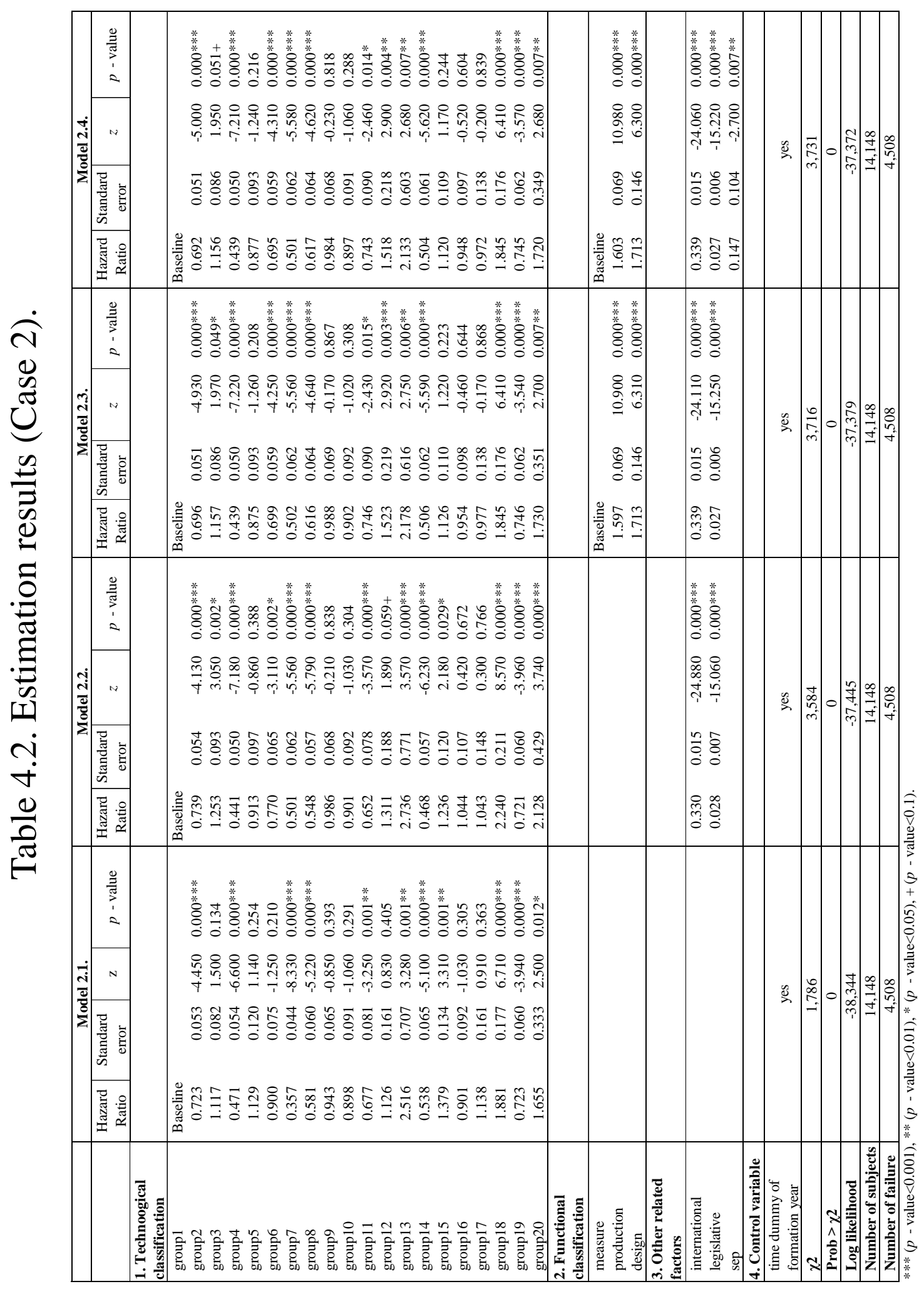




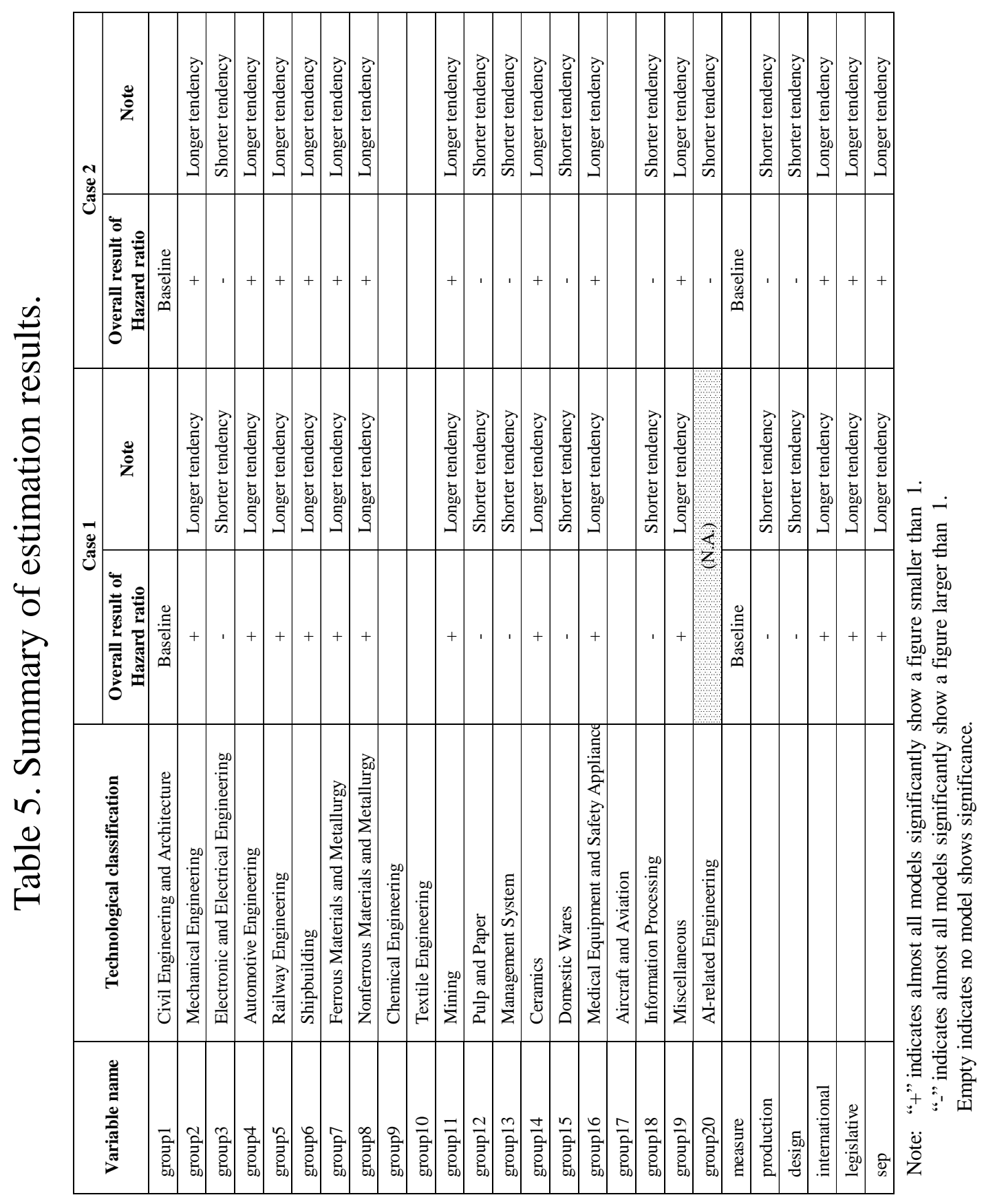


Table 6. Difference of hazard ratio from baseline.

\begin{tabular}{|l|r|r|c|}
\hline \multicolumn{1}{|c|}{ Technological group } & Hazard ratio & Difference from baseline & $\boldsymbol{p}$ - value \\
\hline Automotive Engineering & 0.439 & -0.561 & $0.000^{* * *}$ \\
Ferrous Materials and Metallurgy & 0.501 & -0.499 & $0.000^{* * *}$ \\
Ceramics & 0.504 & -0.496 & $0.000^{* * *}$ \\
Nonferrous Materials and Metallurgy & 0.617 & -0.383 & $0.000^{* * *}$ \\
Mechanical Engineering & 0.692 & -0.308 & $0.000^{* * *}$ \\
Shipbuilding & 0.695 & -0.305 & $0.000^{* * *}$ \\
Mining & 0.743 & -0.257 & $0.014^{*}$ \\
Miscellaneous & 0.745 & -0.255 & $0.000^{* * *}$ \\
Civil Engineering and Architecture & Baseline & 0.000 & N.A. \\
Electronic and Electrical Engineering & 1.156 & 0.156 & $0.051^{+}$ \\
Pulp and Paper & 1.518 & 0.518 & $0.004^{* *}$ \\
AI-related Engineering & 1.720 & 0.720 & $0.007^{* *}$ \\
Information Processing & 1.845 & 0.845 & $0.000^{* * *}$ \\
Management System & 2.133 & 1.133 & $0.007^{* *}$ \\
\hline
\end{tabular}

*** $(p-$ value $<0.001),{ }^{* *}(p-$ value $<0.01), *(p-$ value $<0.05),+(p-$ value $<0.1)$. 


\section{Table A.1. Description of technological contents.}

\begin{tabular}{|l|l|}
\hline \multicolumn{1}{|c|}{ Technological category } & \multicolumn{1}{c|}{ Major contents of formed standards } \\
\hline $\begin{array}{l}\text { A (Civil Engineering and } \\
\text { Architecture) }\end{array}$ & $\begin{array}{l}\text { General structure / Test, inspection, and surveying / Design and planning / Equipment and fittings } \\
\text { / Material and parts / Construction / Construction machinery and tool }\end{array}$ \\
\hline B (Mechanical Engineering) & $\begin{array}{l}\text { Machine basics / Machine parts / FA common / Tool and jig / Machine tools / Optical machine / } \\
\text { Precision machine }\end{array}$ \\
\hline $\begin{array}{l}\text { C (Electronic and Electrical } \\
\text { Engineering) }\end{array}$ & $\begin{array}{l}\text { Measurement and test equipment tools / Materials, electric wire, cables, and electrical appliances / } \\
\text { Electrical equipment, communication equipment, and electronic equipment and parts / Light bulbs, } \\
\text { lighting equipment, wiring equipment, and batteries / Home appliances }\end{array}$ \\
\hline D (Automotive Engineering) & $\begin{array}{l}\text { Test and inspection method / Common parts / Engine / Chassis and body / Electric device and } \\
\text { instrument / Construction vehicle and industrial vehicle / Repair, adjustment, test, and inspection } \\
\text { device / Bicycle }\end{array}$ \\
\hline E (Railway Engineering) & $\begin{array}{l}\text { Railway general / Train line / Signal and security equipment / General railway vehicles / Motor } \\
\text { vehicles / Passenger cars / Cableways }\end{array}$ \\
\hline F (Shipbuilding) & $\begin{array}{l}\text { Hull / Institution / Electric equipment / Instruments and appliances for navigation / Measuring } \\
\text { instruments }\end{array}$ \\
\hline
\end{tabular}

\section{Table A.1. Description of technological contents (continued).}

\begin{tabular}{|c|c|}
\hline Technological category & Major contents of formed standards \\
\hline $\begin{array}{l}\text { G (Ferrous Materials and } \\
\text { Metallurgy) }\end{array}$ & Analysis / Raw materials / Steel materials / Cast iron and pig iron \\
\hline $\begin{array}{l}\text { H (Nonferrous Materials and } \\
\text { Metallurgy) }\end{array}$ & $\begin{array}{l}\text { Analytical method / Raw material / Wrought copper and copper alloys / Other wrought material / } \\
\text { Casting / Functional material / Processing method and appliance }\end{array}$ \\
\hline K (Chemical Engineering) & $\begin{array}{l}\text { Chemical analysis and environmental analysis / Industrial chemicals / Petroleum, coke, and tar } \\
\text { products / Fatty acids, oil and fat products, and biochemical products / Dye materials, } \\
\text { intermediates, dyes, and powders / Pigments and paints / Rubber / Leather / Plastic / } \\
\text { Photographic materials / Chemicals and measuring methods / Reagent }\end{array}$ \\
\hline L (Textile Engineering) & Testing / Inspection / Yarn / Textile / Textile products / Textile processing equipment \\
\hline M (Mining) & Mining / Ore dressing and coal dressing / Transport / Security / Mineral products \\
\hline P (Pulp and Paper) & Pulp / Paper / Paper work / Test and measurement \\
\hline Q (Management System) & Standard substance / Management system \\
\hline R (Ceramics) & $\begin{array}{l}\text { Ceramics / Refractories / Thermal insulation materials / Glass / Glass fibers / Enamel / Cement / } \\
\text { Abrasive material / Special ceramic products / Carbon products / Special equipment for ceramics }\end{array}$ \\
\hline S (Domestic Wares) & $\begin{array}{l}\text { Furniture and indoor decoration / Gas petroleum combustion equipment / Tableware / } \\
\text { Kitchenware / Personal belongings / Shoes / Stationery and office supplies / Sporting goods / } \\
\text { Entertainment goods and music supplies }\end{array}$ \\
\hline
\end{tabular}




\section{Table A.1. Description of technological contents (continued).}

\begin{tabular}{|l|l|}
\hline Technological category & \multicolumn{1}{|c|}{ Major contents of formed standards } \\
\hline $\begin{array}{l}\text { T (Medical Equipment and } \\
\text { Safety Appliances) }\end{array}$ & $\begin{array}{l}\text { Medical electrical equipment / General medical equipment / Dental equipment / Dental materials / } \\
\text { Medical equipment and appliance / Occupational safety / Welfare-related equipment / Sanitary } \\
\text { equipment }\end{array}$ \\
\hline W (Aircraft and Aviation) & $\begin{array}{l}\text { Special materials / Standard parts / Airframe / Engine / Instrument / Electric equipment / Ground } \\
\text { equipment }\end{array}$ \\
\hline X (Information Processing) & $\begin{array}{l}\text { Programming language / Graphics, document processing, and document exchange / OSI, LAN, and } \\
\text { data communication / Output device and recording medium }\end{array}$ \\
\hline Z (Miscellaneous) & $\begin{array}{l}\text { Logistics equipment / Packaging materials, containers, and packaging method / Common test } \\
\text { method / Welding / Radiation / Environment and resource recycling / Factory management and } \\
\text { quality control }\end{array}$ \\
\hline AI-related Engineering & Image processing / Data base \\
\hline
\end{tabular}

Table B.1. List of de jure standards (AI - related standard).

\begin{tabular}{|c|cccc|}
\hline \multicolumn{5}{|c|}{ JIS technological classification } \\
\hline B:Mechanical Engineering & \multicolumn{5}{|c|}{ X: } & Information & Processing \\
\hline B3511 & X0017 & X3005-9 & X4325 & X5302 \\
B3512 & X0025 & X3006-1 & X4326 & X5303 \\
B3521 & X0138-1 & X3006-2 & X4327 & X5304 \\
B3700-21 & X0138-3 & X3006-3 & X4328 & X5304-1 \\
B6311 & X0201 & X3006-5 & X4329 & X5304-2 \\
B6314 & X0202 & X3006-6 & X4330 & X5304-3 \\
& X0207 & X4213 & X4331 & X5304-4 \\
& X0208 & X4214 & X4332-1 & X5305 \\
& X0211 & X4215-1 & X4332-2 & X5306 \\
& X0212 & X4221-1 & X4332-3 & X5308 \\
& X0213 & X4241-1 & X4341 & X5604 \\
& X0221 & X4241-2 & X4345 & X5606-1 \\
& X0221-1 & X4241-5 & X4346 & X5606-2 \\
& X0523 & X4242 & X4350-1 & X5911 \\
& X0652 & X4301 & X4350-2 & X5912 \\
& X0653 & X4302 & X4350-3 & X6133 \\
& X3004 & X4303 & X5055-1 & X6134 \\
X3005 & X4304-1 & X5055-2 & X7199 \\
& X3005-1 & X4304-2 & X5251 & X9010 \\
X3005-10 & X4311 & X5252 & X9201 \\
X3005-13 & X4312 & X5253 & X9204 \\
X3005-14 & X4321 & X5254 & X9205 \\
& X3005-2 & X4322 & X5255 & X9206-1 \\
X3005-3 & X4323 & X5260-1 & X9301 \\
X3005-4 & X4324 & X5301 & \\
\hline
\end{tabular}

Note: The total number $\mathrm{n}=105$ as of 2014 . 
Figure C.1. Effective terms of AI-related standards.

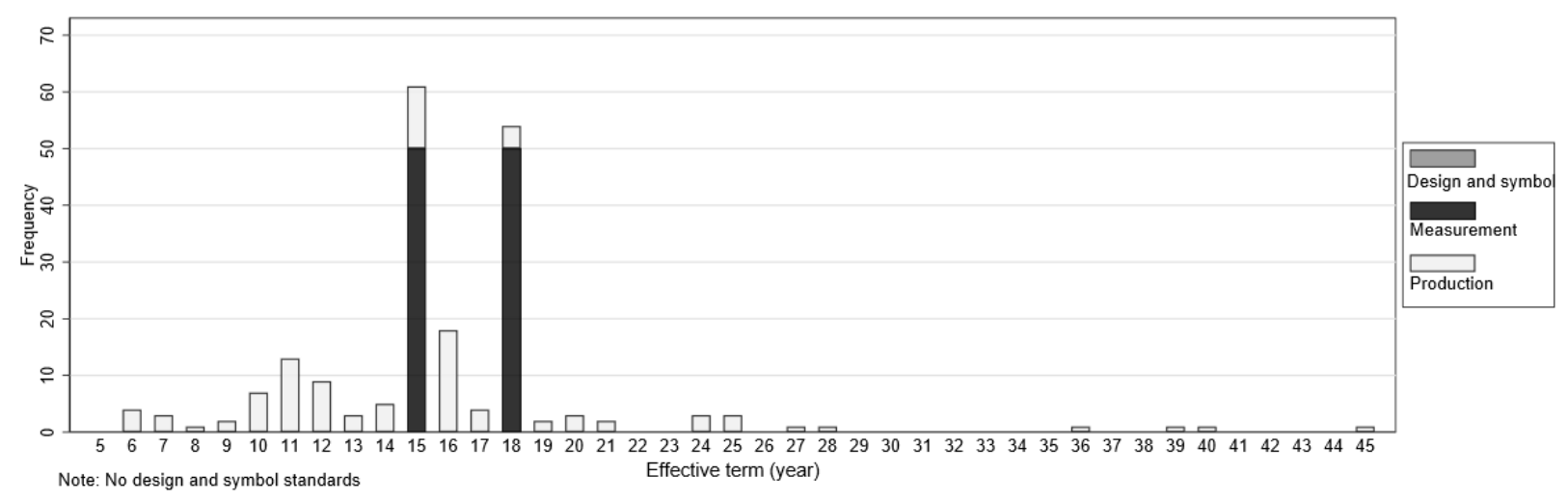

